Ю.В. Стасєв, Г.Г. Бабіч, Ю.І. Заруденська, І.О. Болбас

Харківський національний університет Повітряних Сил ім. І. Кожедуба

\title{
МЕТОДИКА ОЦІНКИ ЕФЕКТИВНОСТІ ФУНКЦІОНУВАННЯ ПРИСТРОЇВ ФОРМУВАННЯ КЕРУЮЧИХ ПОСЛІДОВНОСТЕЙ
}

У статті пропонується методика оцінки ефективності функиіонування механізмів формування керуючих послідовностей для реалізаџії активної завадо- та імітозахисту завадозахисних систем зв'язку $i$ управління на фізичному рівні. Реалізачія активної завадо- та імітозахисту систем зв'язку і управління на фізичному рівні досягається при використанні динамічного режиму функціонування на рівні складних сигналів. В изьому випадку постановка імітаційних та структурних перешкод зловмисником еквівалентна постановиі їм звичайних шумових завад. Максимальна ефективність динамічного режиму функціонування досягається за умови, щзо зловмиснику не відомий закон, який реалізує динамічний режим функціонування $i$ він не може розкрити ией закон формування на заданому інтервалі часу. Отримано математичні вирази, щзо дозволяють сформулювати вимоги до пристроїв формування керуючих послідовностей $і$ оцінити якості керівників послідовностей. Проведено аналіз і розроблена методика оцінки ефективності функціонування механізмів формування керуючих послідовностей для реалізації динамічного режиму функціонування. Встановлено, щзо пристрій формування керуючих послідовностей має забезпечувати високу структурну скритність і високу лінійну складність породжуючих послідовностей. Сформульовано вимоги до пристроїв формування керуючих послідовностей.

Ключові слова: динамічний режим функціонування, пристрої формування керуючих послідовностей, керуючі послідовності, система зв'язку та управління.

\section{Вступ}

Постановка проблеми. Реалізація динамічного режиму функціонування систем зв'язку та управління, як показали дослідження [1-2], забезпечує активний іміто- та завадозахист телекомунікаційних систем керування й зв'язку. Разом з тим, до теперішнього часу залишається невирішеним завдання оцінки пристроїв реалізації динамічного режиму.

Реалізація ефективного динамічного режиму функціонування базується на використанні керуючих послідовностей, закон формування яких не може встановити зловмисник за певний час аналізу керуючої послідовності.

Аналіз останніх досліджень і публікацій. Дослідженням алгоритмів формування псевдовипадкових керуючих послідовностей та аналізу їх властивостей присвячено велика кількість публікацій, наприклад [1-2; 4-6;11-12].

Аналіз проведених досліджень показує, що на теперішній час досліджують тільки структурні властивості керуючих послідовностей та відсутня методика оцінки ефективності функціонування пристроїв формування керуючих послідовностей.

Мета статті. Розробка методики оцінки ефективності функціонування пристроїв формування керуючих послідовностей.

\section{Виклад основного матеріалу}

Під показником ефективності функціонування пристроїв формування керуючої послідовності (ПФКП) будемо розуміти кількісну міру ступеня відповідності реального і необхідного результатів. Під критерієм ефективності функціонування ПФКП будемо розуміти правило, що дозволяє побудувати ПФКП, що характеризується різним ступенем досягнення необхідного результату і здійснити спрямований вибір методів побудови ПФКП з безлічі допустимих.

Завдання формування керуючої послідовності, що задає динамічний режим функціонування, може бути сформульована як відображення $F$ безлічі вхідних сигналів $X$ на елемент іншої безлічі $Y$ (безлічі вихідних сигналів)

$$
y=F(x),
$$

де $x \in\{X\} ; y \in\{Y\}$.

Оператор відображення $F$ визначає систему (пристрій) формування елементів керуючої

послідовності, що крім вхідних і вихідних змінних характеризується сукупністю проміжних змінних $S_{k}, k=1,2, \ldots, q$, що належать деякій безлічі $\{S\}$. Безлічі $\{X\},\{Y\},\{S\}$ звичайно розглядають як унітарні метричні простори. У той же час вони $€$ функціональними просторами, тому що системи функціонують у часі. Безліч $\{T\}$ моментів часу характеризує один 3 можливих станів $S_{i}\left(t_{i}\right)$. Стан 
$S_{i}\left(t_{i}\right)$ визначається як властивостями самої системи, так і вхідними сигналами.

3 урахуванням вище сказаного, для процесу формування керуючої послідовності, що задає динамічний режим функціонування, необхідно задати систему рівнянь

$$
\left\{\begin{array}{l}
S_{i}\left(t_{i}\right)=F\left[t_{i}, S\left(t_{i-1}, t_{i-2}, \ldots\right), x\left(t_{i}\right)\right] ; \\
y(t)=G\left[t, S_{i}, t_{i}\right],
\end{array}\right.
$$

де $F$ і $G$ - відповідно оператори переходів і виходів формуючої системи.

Відповідно до (2) характер відображення $F$ i $G$ визначає властивості простору $\{Y\}$ і можливості технічної реалізації операторів $F$ і $G$.

Практично оператори $F$ i $G$ в (2) характеризують сукупність об'єднаних лінійних і нелінійних елементів. При цьому ефект формування заданих сигналів досягається використанням певних комбінацій первинних сигналів. 3 огляду на вимоги й особливості побудови телекомунікаційних систем керування й зв'язку, оператори $F$ і $G$ реалізують нелінійні процедури формування вихідної безлічі $\{Y\}$.

Аналіз процедур формування керуючих послідовностей дозволяє зробити наступні висновки [3-6]:

- системи керуючих послідовностей можуть бути побудовані для більшості значень $L$;

- складність процедур синтезу й час, необхідний для синтезу ансамблю керуючих послідовностей, збільшується з ростом числа елементів керуючі послідовності зниженням ступеня кореляції між керуючими послідовностями;

- розподіл символів керуючої послідовності повинне задовольняти критерію псевдовипадковості.

Для кількісного опису відповідності реального результату функціонування ПФКП необхідному введемо функцію відповідності [7-9]:

$$
\rho=\rho\left(Y^{\langle m\rangle}, Y_{m p}^{\langle m\rangle}\right),
$$

де $Y_{m p}^{\langle m\rangle}-m$-мірний вектор необхідного результату функціонування ПФКП;

$Y^{\langle m\rangle}-m$-мірний вектор реального результату функціонування ПФКП.

Оскільки $Y^{\langle m\rangle}$ - випадковий вектор, то псевдовипадкова функція кількох випадкових величин, $\epsilon$ випадковою величиною.

3 розглянутого вище сформулюємо зміст необхідного результату функціонування ПФКП у вигляді вектору реального результату функціонування ПФКП [10]:

$$
\begin{gathered}
Y_{m p}^{\langle 8\rangle}=\left\langle P_{m p}, l_{m p}, t_{m p}, F_{m p}\left(y_{i}\right), H_{m p}(Y) ;\right. \\
\left.X H_{m p}(Y / Y), H_{m p}(X / Y), s_{m p}\right\rangle,
\end{gathered}
$$

де $P_{m p}$ - допустима ймовірність події, яка полягає в перекритті двох вихідних керуючої послідовності;

$l_{m p}$ - допустима довжина періоду вихідних керуючої послідовності;

$t_{m p}$ - необхідний безпечний час ПФКП, який визначається часом цінності інформації, що циркулює в системі;

$F_{m p}\left(y_{i}\right)$ - необхідний закон розподілу псевдовипадкової величини $Y$;

$H_{m p}(Y)$ - допустима величина ентропії випадкової величини $Y ; P_{m p}$

$H_{m p}\left(Y_{i} / Y\right)$ - допустима умовна ентропія величини $Y_{i}$ за умови, що відомі значення $Y_{i-1}, Y_{i-2}, \ldots, Y_{1}$;

$H_{m p}(\mathrm{X} / \mathrm{Y})$ - допустима умовна ентропія величини $X$ за умови, що відомі значення величини $Y$;

$S_{m p}$ - допустима продуктивність, що забезпечує нормальне функціонування системи передачі даних (радіоканалу).

Показник ефективності функціонування $W$ визначається як математичне сподівання функції відповідності, тобто:

$$
W=M\left[\rho\left(Y^{\langle m\rangle}, Y_{m p}^{\langle m\rangle}\right)\right] .
$$

Оскільки закон розподілу випадкового вектора невідомий, то при оцінці ефективності функціонування ПФКП складно використовувати підхід, заснований на визначенні математичного очікування. Для цього необхідно дослідити закон розподілу випадкової величини $p$, що потребують проведення складного статистичного аналізу і проведення великого обсягу обчислень. У зв'язку з цим, доцільним $є$ підхід, який передбачає розгляд приватних функцій відповідності для кожної пари відповідних компонент векторів $Y^{\langle m\rangle}$ i $Y_{m p}^{\langle m\rangle}$, тобто:

$$
\rho_{i}=\rho_{i}\left(y_{i}, y_{m p i}\right), \quad i=\overline{1, m} .
$$

Застосовуючи операцію математичного очікування до приватних функцій відповідності $\rho_{1}, \rho_{2}, \rho_{3}, \ldots, \rho_{m}$, можна отримати приватні показники ефективності $W_{1}, W_{2}, \ldots, W_{m}$. Тоді показник ефективності функціонування ПФКП буде являти собою сукупність приватних показників, тобто:

$$
W=\left\langle W_{1}, W_{2}, W_{3}, K, W_{m}\right\rangle .
$$

Завдання оцінки ефективності ПФКП, $з$ точки 
зору поняття показника і критерію, може бути зведена до багатокритеріальної задачі. Для вибору критерію ефективності скористаємося концепцією придатності. Відповідно до прийнятої концепції вибираємо критерій ефективності функціонування ПФКП, при якому кожен компонент вектора реального результату не перевищує (або не нижче) відповідного компонента вектору необхідного результату.

Шляхом аналітичних методів, використання яких можливо після збору зловмисником усілякої інформації про передбачувану структуру генератоpa, режимах його функціонування й вивчення динаміки його роботи, зловмисник намагається або розкрити закон формування псевдовипадкових послідовностей, або побудувати еквівалентну модель пристрою, описувану зовсім іншими співвідношеннями й алгоритмами. У цьому випадку робота зловмисника пов'язана з більшим обсягом обчислень.

Оскільки в цьому випадку зловмисник має у своєму розпорядженні вихідні значення ПФКП $X$ і передбачуваними вхідними значеннями $Y$, то він може визначити середню кількість інформації, що міститься в безлічі значень псевдовипадкової величини $X$ щодо можливих значень псевдовипадкової величини $Y$, відповідно до формули:

$$
I(Y, X)=H(Y)-H(Y / X) .
$$

Найбільш несприятливий випадок для нього $I(Y, X)=0$, , тобто ми повинні забезпечити, щоб:

$$
H(Y)=H(Y / X) .
$$

Це можливо в тому випадку, коли значення $Y_{i}$ утворять повну групу подій і $є$ незалежними один від одного:

$$
p\left(Y_{1}, Y_{2}, \ldots, Y_{i}\right)=p\left(Y_{1}\right), p\left(Y_{2}\right), \ldots, p\left(Y_{i}\right) .
$$

Аналогічно статистичному методу, необхідно забезпечити незалежність $S \in\{V, H\}$.

За допомогою прямого перебору, використовуючи передбачувані сполучення можливих внутрішніх і початкових станів ПФКП, і комбінуючи 3 іншими методами аналізу, зловмисник намагається зламати систему “грубою силою”. Метод не вимагає ніяких знань про ПФКП. Недолік методу - більша обчислювальна складність у випадку великої кількості внутрішніх і початкових станів ПФКП, а також великого періоду послідовності.

Виходячи з вищевикладеного, для оцінки ефективності функціонування ПФКП пропонується використовувати наступну методику.

1. Постановка завдання. На цьому етапі з урахуванням загальних завдань і принципів побудови системи супутникового зв'язку визначаються завдання ПФКП в системі і формалізується необхідний результат функціонування ПФКП, а також розроблясться математична модель ПФКП. Розробляється метод формування псевдо-випадкових чисел або вибирається відомий метод.

2. Аналіз алгоритму функціонування ПФКП. Аналіз ансамблевих властивостей керуючих послідовностей. На даному етапі на основі математичної моделі ПФКП і загальносистемних характеристик здійснюються аналіз алгоритму функціонування ПФКП і теоретичні дослідження його характеристик. Тут визначається безліч вхідних параметрів $U$ і початкових станів $K$, аналізуються правила вибору і розрахунку параметрів ПФКП, на предмет виключення можливості формування вироджених або коротких керуючих послідовностей. На основі отриманих результатів проводиться кількісна оцінка довжини періоду вихідних керуючої послідовності і ймовірності перекриття $P_{n}$, перевіряються умови:

$$
l \geq l_{m p} \text { i } P_{n} \leq P_{m p} .
$$

3. Аналіз структурних властивостей керуючих послідовностей. На основі аналізу алгоритму функціонування ПФКП проводиться теоретична оцінка часу, який потрібен для розкриття закону формування керуючої послідовності $t_{\sigma}$. Для оцінки $t_{\sigma}$ необхідно визначити відстань єдності $l_{0}$, структурну скритність $S_{0}$, потужність ключового безлічі і обчислювальну складність процедури криптоаналізу. Якщо отримана величина $t_{\sigma}$ не задовольняє необхідному рівню, то розробляються правила, які реалізують функцію відображення $y_{i}=f\left(x_{i}\right)$ і забезпечують високі показники структурної скритності та обчислювальної складності процедури криптоаналізу. Тут же розглядаються можливі стратегії криптоаналізу ПФКП і визначається безліч параметрів, що підлягають безумовній захисту. На основі отриманих результатів знову проводиться оцінка $t_{\sigma}$ і перевіряється умова:

$$
t_{\sigma} \geq t_{m p},
$$

де $t_{m p}$ - необхідний безпечний час ПФКП, який визначається часом цінності інформації, що циркулює в системі;

4. Розробка рекомендацій щодо практичної реалізації ПФКП. Таким чином, після проведення комплексу теоретичних досліджень визначається проміжний вектор реального результату:

$$
Y_{n p}^{\langle 3\rangle}=\left\langle P_{n}, l, t_{\sigma}\right\rangle .
$$

Тільки в разі виконання умов рекомендується приступати до експериментальних досліджень.

5. Експериментальна оцінка показника ефективності функціонування ПФКП. Аналіз статистичних і кореляційних властивостей керуючої послідовності.

Оцінка емпіричного закону розподілу псевдовипадкової величини $Y$, визначення ентропійних показників ПФКП вимагає проведення експеримен- 
ту. На даному етапі робіт розробляється програмна модель ПФКП і на основі статистичного аналізу вихідних керуючої послідовності здійснюється оцінка закону розподілу $F\left(y_{i}\right)$ і якісна оцінка ентропійних показників - $H(Y), H\left(Y_{i} / Y\right), H(X / Y)$. Обчислення ентропійних показників ефективності функціонування безпосередньо важко. Застосовуючи статистичні тести, ми можемо опосередковано отримати оцінки ентропійних показників. Перевіривши гіпотези про випадковість і незалежності псевдовипадкових величин, ми 3 довірчою ймовірністю використовуваних критеріїв, можемо відповісти, чи задоволені чи ні вимоги по ентропійних показників.

За результатами випробувань здійснюється статистична оцінка закону розподілу величини $Y$ i формуються гіпотеза $H_{0}$, яка полягає в тому, що емпіричний закон розподілу $F\left(y_{i}\right)$ узгоджується 3 рівномірним. Для оцінки ступеня згоди використовуються критерії узгодженості Пірсона, Колмогорова, Мізеса і Романовського. Крім того, перевіряються гіпотези про незалежність псевдовипадкових величин $Y_{i}$ i $Y_{j}$ та псевдовипадкових величин $X$ i $Y$, тобто:

$$
\begin{aligned}
& H_{1}: F\left(y_{i}, y_{i}\right)=F\left(y_{i}\right) F\left(y_{i}\right) ; \\
& H_{2}: F\left(x_{i}, y_{i}\right)=F\left(x_{i}\right) F\left(y_{i}\right) .
\end{aligned}
$$

3 цією метою будуються діаграми розсіювання i проводиться кореляційний аналіз вихідних керуючої послідовності.

Оскільки в реальній системі використовуються тільки відрізки керуючої послідовності повного періоду, то необхідно перевірити припущення про те, що закон розподілу псевдовипадкової величини $Y$ не змінюється в процесі експерименту. Для цього висувається гіпотеза:

$$
H_{2}: F_{1}\left(y_{i}\right) \equiv F_{2}\left(y_{i}\right),
$$

де $F_{1}\left(y_{i}\right)$ та $F_{2}\left(y_{i}\right)$ - емпіричні розподілу, отримані для двох різних вибірок значень величини $Y$.
Гіпотеза $\mathrm{H}_{2}$ перевіряється 3 використанням критеріїв однорідності.Для отримання додаткової інформації про властивості керуючих послідовностей проводяться перевірки “випадковості”, які здійснюються $з$ використанням критеріїв серій, інверсій і покер-тесту.

За результатами статистичного аналізу здійснюється якісна оцінка ентропійних показників ПФКП i, можливо, виробляються уточнення алгоритму ПФКП і керуючих послідовностей. На заключних етапах досліджень здійснюється оцінка продуктивності ПФКП і перевіряється умова:

$$
S \geq I \equiv S_{m p},
$$

де $S_{m p}$ - мінімальна кількість символів керуючої послідовності, що необхідно для розкриття закону формування послідовностей.

В кінцевому підсумку, за результатами теоретичних i експериментальних досліджень визначається вектор реального результату і векторний показник якості функціонування ПФКП.

Реалізація висновків здійснюється 3 урахуванням всіх отриманих результатів досліджень і вимог, що пред'являються як до ПФКП, так і до системи зв'язку в цілому.

\section{Висновки}

Таким чином, при проектуванні й конструюванні ГПВП необхідно враховувати наступні загальні вимоги:

- вихідні значення генератора повинні бути рівномірно, однорідно й випадково розподілені, некорелюємі;

- наявність високої структурної скритності й лінійної складності породжуваних послідовностей;

- наявність кореляційного імунітету при використанні вузлів, що комбінують;

- наявність достатньої стартової ентропії, тобто непередбачених внутрішніх станів.

\section{Список літератури}

1. Теорія сигнально-кодових конструкцій: монографія / М.І. Науменко, Ю.В. Стасєв, О.О. Кузнецов, С.П. Свсеєв. Х.: ХУПС, 2008. - $541 \mathrm{c}$.

2. Стасєв Ю.В. Умови реалізації динамічного режиму функціонування захисту системи зв'язку та управління / Ю.В. Стасєв, О.О. Мелешенко, І.О. Ткаченко // Системи озброєння і військова техніка. - 2016. - № 12(16). - С. 28-32.

3. Науменко М.И. Методы синтеза сигналов с заданными свойствами / М.И. Науменко, О.О. Кузнецов // Международный научно-теоретический журнал. - 2007. - № 3. - С. 10-17.

4. Формирование больших ансамблей дискретных сигналов с использованием избыточных кодов / Ю.В. Стасев, О.О. Кузнецов, А.М. Носик, Л.Н. Качур // Збірник наукових праць Харківського університету Повітряних Сил. - 2008. № 2(17). - C. 102-110.

5. Discrete Signals with Multi-Level Correlation Function Statistical Methods of Signal and Data Processing / Yu. Stasev, A. Kuznetsov, V. Sai, O. Karpenko // Proceedings National Aviation University "NAU-Druk". - Kyiv, 13-14 October 2010. - 180 p.

6. Метод формування псевдовипадкових послідовностей 3 поліпшеними автокореляційними властивостями / Ю.В. Стасев, Д.О. Медведев, Д.О. Грабенко, Д.В. Жуйков / Системи озброєння і військова техніка. - 2016. - № 4(53). C. 71-76.

7. Вентцель Е.С. Теория вероятностей и ее инженерные приложения / Е.С. Вентцель, Л.А. Овчаров. - М.: Наука, 1988. $-480 \mathrm{c}$. 
8. Ковтун Н.В. Теорія статистики / Н.В. Ковтун. - К.: Знання, 2017. - 399 с.

9. Огірко О.І. Теорія ймовірностей та математична статистика / О.І. Огірко, Н.В. Галайко. - Львів: ДУВС, 2017. 292 c.

10. Теорія ймовірностей та математична статистика / О.Г. Савченко, Н.В. Валько, Г.М. Кавун, Л.В. Кузьмич. Херсон: РВЦ “Колос”, ХДАУ, 2017. - 406 с.

11. Official site NIST.GOV. NIST Selects Winner of Secure Hash Algorithm (SHA-3) Competition. - Available at: http://surl.li/ikab.

12. Mutual correlation of NIST statistical randomness tests and comparison of their sensitivities on transformed sequences [Electronic resource] / A. Doganaksoy, F. Sulak, M. Uguz, O. Seker, Z. Akcengiz // Turkish Journal of Electrical Engineering and Computer Sciences. - 2017. - № 1. - P. 655-665. - Available at: http://surl.li/ikaa.

Надійшла до редколегї 28.10.2020

Схвалена до друку 01.12.2020

\section{Відомості про авторів:}

\section{Стасєв Юрій Володимирович}

доктор технічних наук професор професор

Харківського національного університету

Повітряних Сил ім. І. Кожедуба,

Харків, Україна

https://orcid.org/0000-0002-3893-0313

\section{Бабіч Григорій Григорович}

начальник навчального курсу

Харківського національного університету

Повітряних Сил ім. І. Кожедуба,

Харків, Україна

https://orcid.org/0000-0002-4470-9228

\section{Заруденська Юлія Ігорівна}

курсант-магістрант

Харківського національного університету

Повітряних Сил ім. І. Кожедуба,

Харків, Україна

https://orcid.org/0000-0003-2074-9919

Болбас Іван Олександрович

курсант-магістрант

Харківського національного

університету Повітряних Сил ім. І. Кожедуба,

Харків, Україна

https://orcid.org/0000-0003-0045-630X

\section{Information about the authors:}

Yuriy Stasyev

Doctor of Technical Sciences Professor

Professor

of Ivan Kozhedub Kharkiv

National Air Force University,

Kharkiv, Ukraine

https://orcid.org/0000-0002-3893-0313

\section{Hryhoriy Babich}

Head of the Training Course

of Ivan Kozhedub Kharkiv

National Air Force University,

Kharkiv, Ukraine

https://orcid.org/0000-0002-4470-9228

\section{Yuliia Zarudenska}

Master Cadet

of Ivan Kozhedub Kharkiv

National Air Force University,

Kharkiv, Ukraine

https://orcid.org/0000-0003-2074-9919

\section{Ivan Bolbas}

Master Cadet

of Ivan Kozhedub Kharkiv

National Air Force University,

Kharkiv, Ukraine

https://orcid.org/0000-0003-0045-630X

\title{
МЕТОДИКА ОЦЕНКИ ЭФФЕКТИВНОСТИ ФУНКЦИОНИРОВАНИЯ УСТРОЙСТВ ФОРМИРОВАНИЯ УПРАВЛЯЮЩИХ ПОСЛЕДОВАТЕЛЬНОСТЕЙ
}

\author{
Ю.В. Стасев, Г.Г. Бабич, Ю.И. Заруденская, И.А. Болбас
}

В статье предлагается методика оценки эффективности функиионирования устройств формирования управляюших последовательностей для реализации активной помехо- и имитозащчиты помехозащищенных систем связи и управления на физическом уровне. Реализация активной помехо- и имитозащиты систем связи и управления на физическом уровне достигается при использовании динамического режима функиионирования на уровне сложных сигналов. $B$ этом случае постановка имитационных и структурных помех злоумышленником эквивалентна постановке им обычных шумовых помех. Максимальна эффективность динамического режима функиионирования достигается при условии, что злоумышленнику не известен закон, реализующий динамический режим функиионирования и он не может раскрыть этот закон формирования на заданном интервале времени. Получены математические выражения, позволяющие сформулировать требования к устройствам формирования управляющих последовательностей и оценить свойства управляющих последовательностей. Проведен анализ и разработана методика оиенки эффективности функционирования устройств формирования управляющих последовательностей для реализации динамического режима функиионирования. Установлено, что устройство формирования управляющих последовательностей должно обеспечивать высокую структурную скрытность и высокую линейную сложность порождаюшихся последовательностей. Сформулированы требования к устройствам формирования управляющих последовательностей.

Ключевые слова: динамический режим функционирования, устройства формирования управляющих последовательностей, управляющие последовательности, система связи и управления. 


\section{METHODS OF EVALUATION OF EFFICIENCY OF FUNCTIONING DEVICES OF FORMATION} OF CONTROL SEQUENCES

Yu. Stasyev, H. Babich, Yu. Zarudenska, I. Bolbas

The article proposes a method for evaluating the effectiveness of the functioning of devices for the formation of control sequences for the implementation of active noise protection and imitation protection of noise-immune communication and control systems at the physical level. The implementation of active noise and imitation protection of communication and control systems at the physical level is achieved using a dynamic mode of operation at the level of complex signals. In this case, the setting of imitation and structural interference by an intruder is equivalent to the setting by him of ordinary noise interference. The maximum efficiency of the dynamic mode of operation is achieved provided that the attacker does not know the law that implements the dynamic mode of operation and he cannot reveal this law of formation over a given time interval. Mathematical expressions have been obtained that make it possible to formulate requirements for devices for generating control sequences and evaluate the properties of control sequences. The analysis is carried out and a technique for evaluating the efficiency of functioning of devices for forming control sequences for the implementation of a dynamic mode of operation is developed. It was found that the device for generating control sequences should provide high structural secrecy and high linear complexity of the generated sequences. Requirements for devices for generating control sequences are formulated.

Keywords: dynamic mode of operation, control sequence generating devices, control sequences, communication and control system. 